\title{
How to digitalize inseparable service processes: the enabling role of internal and external support for innovation
}

\author{
Anna Moker ${ }^{1}$ (D) Prisca Brosi ${ }^{2} \cdot$ Isabell M. Welpe $^{1,3}$
}

Received: 30 November 2018/Accepted: 24 June 2020/Published online: 4 July 2020

(C) The Author(s) 2020

\begin{abstract}
Across industries, firms face the need to digitalize their service processes, i.e., transform the service delivery from a physical into a digital form or enhance it through digital technologies. Therefore, one important challenge can arise due to the inseparability of service processes, which describes the necessity for a customer to consume a service the moment which a service provider produces it. Since existing research has failed to examine inseparability as a predictor of service digitalization, this study aims to explore whether inseparability hinders the digitalization of service processes and whether internal support in form of innovation culture and external support from third parties can help to mitigate the influence of inseparability. Data from an online survey of 204 German service employees and managers confirm our hypotheses. These results demonstrate to practitioners that although it may be more difficult to digitalize service processes due to their inseparability, firms may rely on internal and external support for innovation to overcome this challenge.
\end{abstract}

Keywords Digitalization · Service process · Inseparability · External support for innovation · Internal support for innovation

Anna Moker

anna.moker@tum.de

1 Chair for Strategy and Organization, TUM School of Management, Technical University of Munich, Arcisstr. 21, 80333 Munich, Germany

2 Kühne Logistics University, Großer Grasbrook 17, 20457 Hamburg, Germany

3 Bavarian Institute of Bavarian State Institute for Higher Education Research and Planning (IHF), Prinzregentenstraße 24, 80538 Munich, Germany 


\section{Introduction}

Firms in many different industries currently face the need to digitalize their services to stay competitive on the market (Hess et al. 2016). Therefore, digitalization refers to the transformation of services from a physical into a digital form by means of digital technologies (Fichman et al. 2014). This transformation involves either the development of new digital services or the enhancement of existing services and the ways to deliver them through digital technologies (Storey et al. 2016; Troilo et al. 2017). In the latter, digital elements are "infused" (Forkmann et al. 2017; Josephson et al. 2016) into the delivery of existing services (Green et al. 2016).

The digitalization of service processes can offer companies many benefits (Rust and Huang 2014), including efficiency gains (Sabherwal and Jeyaraj 2015), better geographical accessibility of services (Cho and Park 2003), improved service quality, and personalization of services with deeper customer communication (Rust and Huang 2014). Yet, despite these potential benefits, the digitalization of service processes in many firms is still in its infancy (Overby et al. 2010). Major reasons for this are the difficulties in digitalizing service processes that arise for service providers (Green et al. 2016) and customers (Paluch and Blut 2013) due to inseparability.

Inseparability of service processes indicates the degree to which service production by a service provider and its use by a customer need to occur simultaneously (Lovelock and Gummesson 2004; Zeithaml et al. 1985). Inseparability of service processes can hinder their digitalization due to three main reasons. First, inseparability of service processes typically involves the physical presence of a customer at a service facility (Martin 2012; Moeller 2010). This presence is associated with the need of physical interaction with people and objects (Lovelock 1983), the relationship development between a service provider and a customer (Alam 2006) or among customers (Lovelock and Gummesson 2004), as well as the need of synchronous actions of providers and customers (Zeithaml et al. 1985; Vargo and Lusch 2004). For instance, traditional educational service processes are often characterized by a high degree of inseparability (Moeller 2010; Javalgi et al. 2009) when they require the physical presence of a student at an educational facility (Overby 2008). Traditional education services include, for example, demonstrating practical investigations in the laboratory or performing technical tests by instructors and students. Furthermore, classroom-based learning has elements of inseparability, e.g., in lectures or question-answer interactions, discussing a topic with a class or providing immediate feedback (Overby 2008). Because it is difficult to transfer these characteristics to a digital environment (Overby 2012), inseparable service processes are less amenable to digitalization (Overby 2008).

Second, due to customer participation in the delivery of inseparable services (Lovelock and Gummesson 2004), customer experience during it is crucial for the success of digitalization (Biemans et al. 2016; de Brentani 1991; Grover et al. 2018). However, customer reactions to the digitalization of inseparable service processes cannot be fully anticipated beforehand (Storey et al. 2016). For instance, entertainment services with live performances are highly inseparable (Lovelock and 
Gummesson 2004; Moeller 2010). As Grover et al. (2018) explain, customers might value the introduction of digital initiatives such as online automated ticket reservations based on prior preferences in these services, but might be dissatisfied with an automated inclusion of further options, such as parking, snacks, and dinner reservations in their online reservation. Thus, organizations hesitate to implement digitalization projects concerning inseparable service processes (Storey et al. 2016).

Third, the digitalization of inseparable service processes may be further complicated by related challenges such as a loss of physical reality and physical feedback in a digital process (Green et al. 2016). For example, service providers can be confronted by such challenges in highly inseparable health care services (Green et al. 2016). In telehealth-based service processes, health care providers are likely to experience the loss of physical feedback in the digital consultation, because they cannot conduct a hands-on examination of their patients (Green et al. 2016). Overall, it appears to be more difficult to digitalize inseparable service processes (Overby 2008).

However, despite the presence of inseparability, some firms still succeed in digitalizing their service processes (Lovelock and Gummesson 2004; Overby 2012; Grover et al. 2018). These firms, for instance, employ cognitive automation tools to handle student inquiries in higher education (Lacity et al. 2018), rely on radiofrequency identification technology to offer customers a seamless experience at entertainment facilities (Ives et al. 2016), or encourage the use of a telehealth system by specialists, nurses, and managers to help them adjust to the telehealthbased service delivery (Singh et al. 2015). Thus, the relation between inseparability and the digitalization of service processes appears to be less clear than is generally assumed (Green et al. 2016; Paluch and Blut 2013; Keh and Pang 2010). Particularly, some firms appear to possess unique organizational resources (Barney 1991) that may help them to digitize their service process despite inseparability (Gumusluoğlu and Ilsev 2009). Such resources that can leverage digitalization are likely to be presented by the firm's innovation resources (e.g., Storey et al. 2016; Helfat and Raubitschek 2018; Vial 2019): the internal (Barney 2001) and external (Das and Teng 2000) support for innovation.

Internal support for innovation refers to the innovation orientation of firm culture (Gumusluoğlu and Ilsev 2009; Stock and Zacharias 2011). It drives organizational innovation by helping to achieve success in new services (Storey and Hughes 2013), improve new product frequency (Stock et al. 2017), and foster the service delivery innovation (Chen et al. 2009). External support for innovation encompasses resource- and knowledge-based support from parties external to the organization (Gumusluoğlu and Ilsev 2009). It promotes organizational innovation by facilitating the introduction of new and improved services (Chen et al. 2011) through providing new ideas, expertise, and technological assistance for innovation development (Pittaway et al. 2004) and incorporating customer needs and views (Melton and Hartline 2010). Therefore, both internal (Barney 2001) and external (Das and Teng 2000) support for innovation can facilitate a complex digitalization process of inseparable services processes, help to better anticipate the potential customer reactions to it (Storey et al. 2016) and support to address other challenges that companies face (Green et al. 2016). 
Therefore, this study empirically investigates the negative effect of inseparability on the digitalization of service processes, and whether internal and external support for innovation can help to mitigate the hindering role of inseparability. To answer these research questions, we conducted a cross-industrial online survey of 204 service employees and managers from Germany to widen service innovation research (Storey et al. 2016) by making three theoretical contributions. First, we provide empirical evidence on the hindering role of inseparability on the digitalization of service processes (Biemans et al. 2016) by showing that it may be more difficult to digitalize highly inseparable service processes than more separable ones (Overby 2008). Second, in doing so, we consider inseparability in line with established studies from the service field as a matter of degree (Lovelock and Gummesson 2004), not of fact, as had been done in service innovation research (Storey et al. 2016). This allows us to address inseparability and its impact on the digitalization of service processes more precisely (Lovelock and Gummesson 2004). Third, we aim to demonstrate that the hindering effect of inseparability on the digitalization of service processes can be mitigated through internal and external support for innovation. Hence, we show that inseparability of service processes should not be considered as an inevitable, but rather as a formable characteristic of service processes (Lovelock and Gummesson 2004; Vargo and Lusch 2004). Furthermore, we also extend the list of outcomes (Storey et al. 2016) that can be addressed by internal and external support for innovation.

Our study has also practical contributions. First, we show that service delivery indeed constitutes a significant challenge when organizations aim to digitalize their service processes. Therefore, we recommend firms to examine their service processes with respect to the degree of their inseparability prior to implementing digitalization projects. Second, we demonstrate that firms can rely on internal and external support for innovation to manage these challenges successfully. Hence, we advise companies to apply both types of innovation support in their digitalization projects extensively. For instance, firms should internally promote innovationoriented behaviors among their members and reach out externally by applying for governmental funding, searching for cooperation with universities, and involving customers in the digitalization process.

\section{Theoretical background and hypotheses}

\subsection{Inseparability of service processes and digitalization}

Service processes can vary in their degree of inseparability (Lovelock and Gummesson 2004). In service processes with a high degree of inseparability, a customer has to use the service as soon as a service provider produces it (Zeithaml et al. 1985). Therefore, such service processes require an interaction between both parties and cannot take place without a customer (Vargo and Lusch 2004). These service processes typically involve physical acts performed on customer bodies, such as health care and passenger transportation services, or nonphysical acts to 
customer minds, such as live performances in entertainment and consulting (Lovelock and Gummesson 2004).

In contrast, in service processes with a low degree of inseparability, a customer uses the service after a service provider has produced it (Lovelock 1983). Such service processes do not require customer participation or presence in the actual service provision. Moreover, customers often do not even have to enter the service facility and may not meet the service employees personally (Lovelock 1983). These service processes often involve physical acts to objects belonging to customers, such as repair and maintenance services, or information processing, such as insurance and research services (Lovelock and Gummesson 2004).

A high or low degree of inseparability of service processes can matter for their innovation in general (Storey et al. 2016) and their digitalization in particular (Dotzel et al. 2013). First, as service processes with a high degree of inseparability typically involve the physical presence of a customer at a service facility (Martin 2012; Moeller 2010), they incorporate physical interactions between people and objects (Lovelock 1983). Therefore, they also involve sensory experiences for customers. Second, the interaction of a customer with a service provider (Berry et al. 2002) or other customers (Lovelock and Gummesson 2004) in such processes usually leads to a close contact between these parties. This contact is likely to lead to a relationship development between a customer and service employees or other customers (Alam 2006). Third, a customer often participates in highly inseparable service processes by choosing from available options, contributing own ideas or taking over some tasks, for example (Ostrom et al. 2010). Due to these reasons, both a customer and a service provider have to perform synchronous actions in such processes (Zeithaml et al. 1985). According to the Process Virtualization Theory (Overby 2008), it is difficult to reproduce the characteristics of sensory experiences, relationship development, and synchronous actions when transferring a process to a digital environment. Therefore, processes bound to such requirements are less amenable to digitalization (Overby 2012). Hence, we hypothesize:

H1. The higher the degree of inseparability of service processes, the lower the degree of their digitalization.

\subsection{Overcoming inseparability with internal and external support for innovation}

Firms differ in the resources they possess to overcome obstacles, according to the resource-based view (Barney 1991). Such resources include any tangible or intangible internal strengths of a firm, such as knowledge, ability, technology, contacts, or processes (Barney 2001). Additionally, such resources may also include resources obtained from cooperation with external parties (Das and Teng 2000). However, these resources are not easily transferrable across firms, creating differences among firms that can be long lasting (Barney 1991). These differences result in a unique set of resources and relationships for every firm (Barney 1991), constituting the firm's competitive advantage (Barney 2001). 


\subsubsection{Internal support for innovation}

Internal support for innovation refers to the innovation orientation of firm culture (Gumusluoğlu and Ilsev 2009; Stock and Zacharias 2011). It reflects to what extent a firm encourages, recognizes, and rewards innovation (Gumusluoğlu and Ilsev 2009) in its internal values (e.g., emphasis on innovativeness and creativity), norms (e.g., appreciation of unconventional ideas), and artifacts (e.g., attractive discussion areas) (Stock and Zacharias 2011).

Prior research on service innovation has shown that organizational characteristics that correspond with internal support for innovation, such as innovation strategy, team empowerment, internal communication, and senior management support, especially facilitate the innovation success of inseparable service processes (Storey et al. 2016). In fact, internal support for innovation can help to overcome the obstacle of inseparability to the digitalization of service processes in several ways. First, internal support for innovation creates an innovation mentality within a firm (Stock and Zacharias 2011) that encourages employees and managers to think about their service processes more creatively, search for new solutions for the digitalization of highly inseparable processes, and experiment with them (Stock and Zacharias 2011). Furthermore, internal support for innovation is likely to attract creative and innovation-oriented candidates to the firm (Miron et al. 2004) bringing possibly new ideas about the digitalization of highly inseparable service processes. As a result of this, organizational members can find new solutions for conducting highly inseparable service processes in a more separable (Lovelock 1983) or digitalized way. They can even find a way to introduce an equivalent digital service that would substitute the old service process (Paluch and Blut 2013).

Second, internal support for innovation pays a particular attention to involving customers in the digitalization projects, by, e.g., appreciating their ideas and introducing digital innovations to them (Stock and Zacharias 2011). Furthermore, internal support for innovation helps to ensure customer involvement in service digitalization projects by allocating enough resources, such as personnel, funding, and time, to them (Gumusluoğlu and Ilsev 2009). Therefore, internal support for innovation can help to better anticipate and address customer reactions to the digitalization of highly inseparable service processes.

Third, due to encouraging innovative ideas of organizational members, internal support for innovation can ensure that new creative solutions to arising challenges such as service employees' uncomfortableness with a digitalized process or technological problems are developed quickly and non-bureaucratically (Gumusluoğlu and Ilsev 2009; Stock and Zacharias 2011). The arising challenges can also be addressed through allocating enough human, financial, and technological resources to service digitalization projects to offer a profound training for service process employees and a reliable technological infrastructure for a digitalized service process (Gumusluoğlu and Ilsev 2009; Green et al. 2016). Overall, internal support for innovation can help to mitigate the obstacles, created by the inseparability for the digitalization of service processes. Therefore, we hypothesize:

H2. Internal support for innovation moderates the relationship between the inseparability of service processes and digitalization, such that the negative effect of 
inseparability on digitalization will be weaker the higher the degree of internal support for innovation.

\subsubsection{External support for innovation}

Firms may also benefit from resource- and knowledge-based support for innovation from external parties (Barney 2001; Das and Teng 2000). Knowledge gained from customers with regards to their needs and possible solutions to these needs (Chang and Taylor 2016) may help to understand the surrounding conditions of digitalization. The experience and skills of business partners (Ordanini and Parasuraman 2010) may provide feasible ways to digitalize. Furthermore, information and technical assistance from universities, financial and technical support from support organizations (Gumusluoğlu and Ilsev 2009), and tax reliefs from the government (Thomas et al. 2016) may ease the actual digitalization of service processes.

In sum, external support for innovation can help to overcome the obstacle of inseparability to the digitalization of service processes in three important ways. First, external knowledge may provide wider expertise on digitalization, such as new technological knowledge (Pittaway et al. 2004), process-related expertise (Chen et al. 2011), support in acquiring new technology (Gumusluoğlu and Ilsev 2009), and creating advantageous conditions for digitalization (Thomas et al. 2016). On the basis of this support, a firm can find new solutions for conducting highly inseparable service processes in a more separable (Lovelock 1983) or digitalized way or even substitute them with equivalent digital service processes (Paluch and Blut 2013).

Second, external support for innovation can come from customers (Chang and Taylor 2016). Customers can be involved in the digitalization projects by helping to identify the existing digitalization potential of a firm's service process, generate, and evaluate new ideas with respect to its digitalization, define the desired design of a digitalized service process, test it, and provide comprehensive feedback to the firm (Melton and Hartline 2010). Additionally, best practices from other organizations (Ordanini and Parasuraman 2010) and tax reliefs from the government (Thomas et al. 2016) can help to reduce the risk of introduction of digitalized service processes.

Third, external support for innovation, coming from universities, support organizations, and business partners can offer firms resources, such as technological and professional assistance as well as coaching (Gumusluoğlu and Ilsev 2009). These resources can help firms to deal with technological and personal challenges, which arise due to the digitalization of highly inseparable service processes. Overall, external support could help to mitigate the obstacles, created by inseparability, for the digitalization of service processes. Therefore, we hypothesize:

H3. External support for innovation moderates the relationship between the inseparability of service processes and digitalization, such that the negative effect of inseparability on digitalization will be weaker the higher the degree of external support for innovation. 


\section{Methods}

To test our hypotheses, we conducted a cross-industrial online survey in Germany. As participants were required to have proficient knowledge about service processes, the survey targeted persons who directly worked in service processes or were responsible for them. We recruited these participants via a German online research panel.

\subsection{Sample and procedure}

Participants were preselected to work in service industries by the panel provider. In addition, we implemented a screen out question at the beginning of the survey asking participants if they currently worked in a service process and/or were responsible for it. In asking this question, we provided a definition of a service process as a sequence of activities of a service provider involving the use of resources and competencies to benefit another party (Vargo and Lusch 2004) and showed examples, such as maintenance of industrial large-scale plants, strategic consulting, mobile nursing care, or teaching in the middle school. Of the 458 persons who clicked on the survey link following the invitation by the service provider, 278 passed this question. To exclude those participants who just clicked through the survey, we implemented three quality check questions, e.g., "To be able to continue the survey, please click on "strongly agree (7)"". Another 13 persons had to be excluded, because they failed to correctly respond to at least one of these quality check questions. Out of the remaining 265 participants, 61 did not complete the survey. This resulted in 204 completed survey responses.

The average age of the survey participants was 45 years $(\mathrm{SD}=11.00) ; 104$ $(51 \%)$ participants were female. Furthermore, 88 (43\%) respondents had managerial responsibility. The participants worked in different organizational departments, such as customer support $(N=43,21 \%)$, administration $(N=31,15 \%)$, human resources $(N=21,10 \%)$, sales $(N=15,7 \%)$, management $(N=11,5 \%)$, IT $(N=11,5 \%)$, assembly $(N=8,4 \%)$, research and development $(N=7,3 \%)$, logistics $(N=6,3 \%)$, quality management $(N=6,3 \%)$, and other $(N=40,20 \%)$. The participants were mainly employed in education and health services $(N=63$, $31 \%)$, trade, transportation, and utilities $(N=31,15 \%)$, and public administration $(N=23,11 \%)$. The rest accounted for finance $(N=18,9 \%)$, professional and business services $(N=13,6 \%)$, leisure and hospitality $(N=11,5 \%)$, information $(N=8,4 \%)$, goods-producing industries $(N=5,3 \%)$, and other services $(N=31$, $15 \%)$.

\subsection{Measures}

\subsubsection{Dependent variable}

To measure the digitalization degree of service processes, we used five items that represented the main characteristics of digitalization, namely the use of an IT-based 
mechanism (Overby 2008), place dependency (Sambamurthy et al. 2003), time dependency (McFarland and Ployhart 2015), digital information storage (McFarland and Ployhart 2015), and the overall IT-based proportion of the service process (Thomas et al. 2016). Consistent with prior research, we measured the first four items using a seven-point Likert scale. The IT-based proportion of the service process was measured in percent (Thomas et al. 2016). We standardized all items and computed the reflective measure of digitalization based on their means. The scale provided high reliability $(\alpha=0.92)$.

We verified the internal consistency of the developed instrument by conducting a pretest with 120 university students, whose average age was 22 ( $\mathrm{SD}=2.73), 45$ (38\%) participants were female. We asked the students to read a description of a service process, namely university teaching, at a hypothetical university called "WiWi". In this description, we randomly varied the digitalization degree of the service delivery. We presented each student with the description of a service process that was either digitalized ("All courses are videotaped and provided via an online platform to students") or not digitalized ("All courses take place on the WiWi campus and require student attendance"). Subsequently, the students rated the digitalization degree of this service process. The scale of our instrument proved internally consistent $(\alpha=0.95)$. Furthermore, independent samples $t$ tests examining the effect of the systematic variation of digitalization on the assessment of the digitalization of a service process were significant, $t(118)=10.06, p<0.001$. Thus, our measure successfully discriminated between low and high degrees of digitalization.

\subsubsection{Independent variables}

We measured inseparability of service processes with four items (Lievens and Moenaert 2000), e.g., "The production of this service and the consumption of this service by the customer happen simultaneously". This measure highlights both the simultaneity of service production and consumption, which characterizes inseparability according to its definition (Lovelock and Gummesson 2004; Zeithaml et al. 1985), and direct customer contact, which the concept of inseparability is primarily based on (Vargo and Lusch 2004). All items were measured on a five-point scale, ranging from "to a very little extent" (1) to "to a very large extent" (5). Reliability was $\alpha=0.78$.

We measured internal support for innovation (Gumusluoğlu and Ilsev 2009) with nine items, taken from Stock and Zacharias's (2011) multidimensional scale of innovation orientation of culture. In accordance with the definition of internal support for innovation, this scale allowed us to assess the degree to which a firm supported an innovation climate (Gumusluoğlu and Ilsev 2009; Scott and Bruce 1994) by pushing organizational members toward innovation and creating an internal innovation mentality (Stock and Zacharias 2011). Following previous research, we summed over the six items subscale targeting on values and norms, e.g., "In our company, we particularly emphasize innovativeness and creativity", as well as the three items subscale focusing on artifacts, e.g., "In our company, stories of exemplary innovation-oriented behavior of executives (e.g., founders, chief 
executives, managers) circulate". All items were measured on a seven-point Likert scale. Reliability was $\alpha=0.73$.

We adapted the measure for external support for innovation by Gumusluoğlu and Ilsev (2009) by asking participants about the extent to which their company has received resource- and/or knowledge-based support (e.g., financial support or technical assistance) for its innovation projects from external organizations within the last 3 years. As external organizations, we took customers, other companies, research institutes/universities, support organizations, and the government, because these parties constitute the main external stakeholders of a company (Gumusluoğlu and Ilsev 2009; Xue et al. 2008). The resulting five-item measure allowed us to assess the amount of the innovation support, which comes from different external sources, most comprehensively (Ansoff 1965; Bourgeois III 1984; Hitt and Tyler 1991; Porter 1980; Xue et al. 2008). Ratings were given using a seven-point Likert scale, which proved highly reliable, $\alpha=0.86$.

\subsubsection{Control variables}

We controlled for firm age, firm size, industry, as well as market dynamism and technology turbulence, as these variables have been shown to influence a firm's innovation practices and are, therefore, frequently accounted for in service innovation studies (Arnold et al. 2011). Firm age was measured as the number of years since the firm's foundation (Chen et al. 2011). Firm size was operationalized as the logarithm of the number of firm's employees (Chen et al. 2011). We controlled for industry by creating a dummy variable for the three largest industries (Yanadori and Cui 2013). Market dynamism $(\alpha=0.78)$ and technology turbulence $(\alpha=0.79)$ were each measured with three-item scales on a seven-point Likert scale taken from Arnold and others (2011). Furthermore, we controlled for two characteristics of service processes (Biemans et al. 2016): intangibility and perishability. Both are related to inseparability (Kaplan and Haenlein 2006; Cloninger and Oviatt 2006) and may also be connected to digitalization (Alexiev et al. 2018; Storey et al. 2016). Intangibility $(\alpha=0.73)$ and perishability $(\alpha=0.72)$ were measured with four and three items respectively on a five-point scale ( $1=$ "to a very little extent" to $5=$ "to a very large extent") developed by Lievens and Moenart (2000).

\section{Results}

Descriptive statistics and correlations are presented in Table 1. Although some correlations between the independent variables were significant, none of the correlation coefficients exceeded the critical value, which is generally considered to be 0.80 or higher (Hair et al. 2009; Kamasak et al. 2016; Saunders et al. 2007). Furthermore, all the variance inflation factors (VIF) for all variables were far below the value of 5, which is considered as problematic (Hair et al. 2013; Kamasak et al. 2016). Therefore, multicollinearity does not appear to present a problem for our data. To test our data for the presence of common method bias, we conducted 


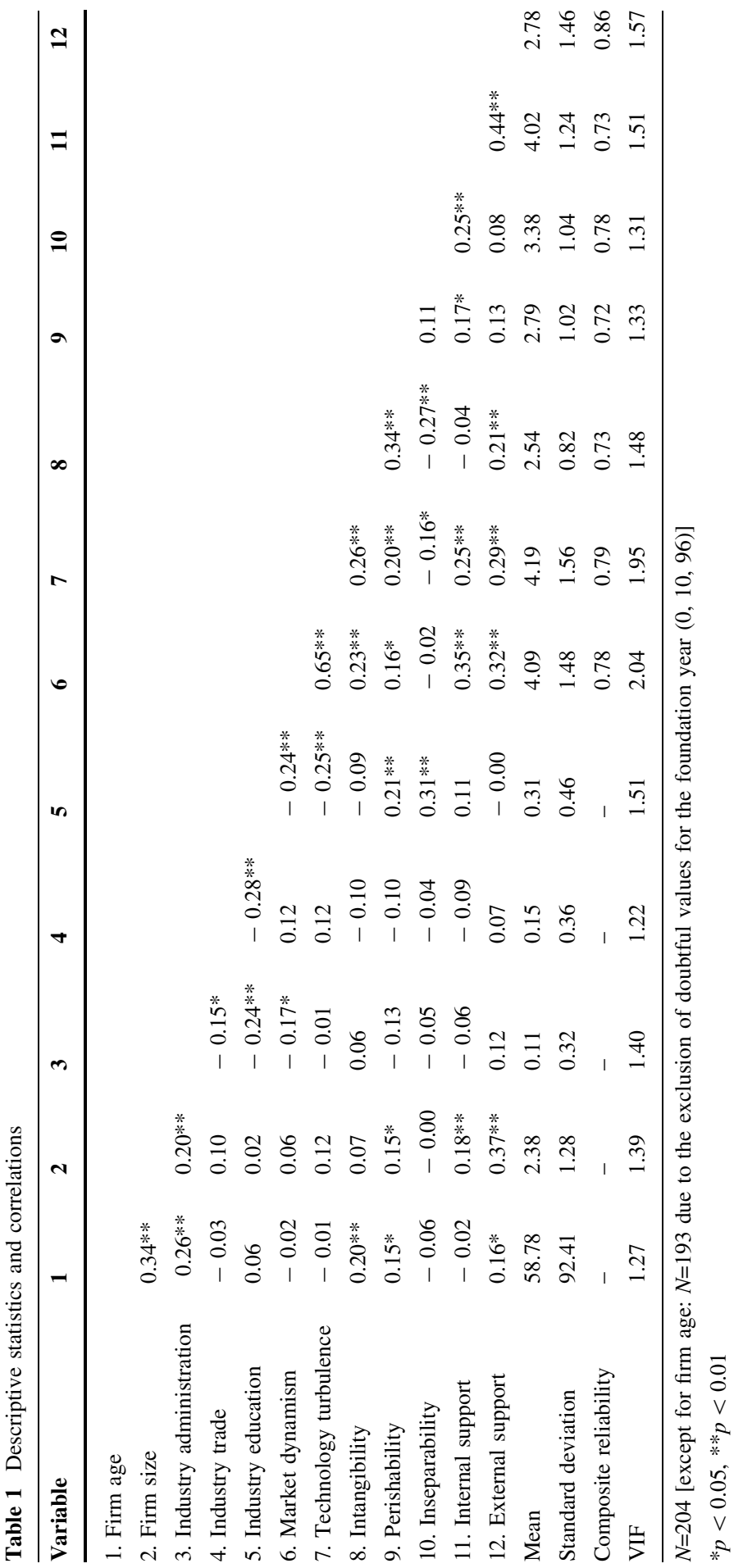


Harman's one-factor test (Podsakoff et al. 2003). We loaded all the variables from our study into the exploratory factor analysis and examined the unrotated factor solution (Podsakoff et al. 2003). As a result, one factor explained only $18.5 \%$ of the total variance, so common method bias does not appear to influence our data.

We examined our data by conducting a linear regression analysis in SPSS 25 and using standardized variables before creating interaction terms. We applied the Johnson-Neyman technique (Hayes and Matthes 2009) to compute the significance regions of the simple slopes of interaction terms. Table 2 depicts our regression results.

In a first step of our regression analysis, we tested only the effects of control variables on digitalization (Model 1). In a second step, we also entered the main effect of inseparability of a service process on digitalization (Model 2). In a third step of our analysis, we added the main effects of internal and external support for innovation on digitalization (Model 3). In a fourth step, we entered the interaction term between inseparability and internal support for innovation (Model 4). In a last

Table 2 Results of regression analysis

\begin{tabular}{|c|c|c|c|c|c|}
\hline & Model 1 & Model 2 & Model 3 & Model 4 & Model 5 \\
\hline \multicolumn{6}{|l|}{ Control variables } \\
\hline Firm age & 0.03 & 0.01 & 0.02 & -0.01 & 0.00 \\
\hline Firm size & -0.04 & -0.03 & -0.09 & -0.09 & -0.08 \\
\hline \multicolumn{6}{|l|}{ Industry } \\
\hline Administration & 0.04 & 0.06 & 0.04 & 0.06 & 0.07 \\
\hline Trade & -0.11 & -0.10 & -0.10 & -0.08 & -0.08 \\
\hline Education & $-0.22 * *$ & $-0.15^{\dagger}$ & $-0.17 *$ & $-0.16^{*}$ & $-0.15^{*}$ \\
\hline Market dynamism & -0.04 & 0.02 & -0.04 & -0.01 & 0.00 \\
\hline Technology turbulence & $0.41 * * *$ & $0.35^{* * *}$ & $0.33 * * *$ & $0.29 * *$ & $0.28 * *$ \\
\hline Intangibility & 0.02 & -0.06 & -0.07 & -0.07 & -0.08 \\
\hline Perishability & 0.00 & 0.05 & 0.05 & 0.05 & 0.03 \\
\hline \multicolumn{6}{|l|}{ Main effects } \\
\hline Inseparability & & $-0.26 * * *$ & $-0.29 * * *$ & $-0.29 * * *$ & $-0.28 * * *$ \\
\hline Internal support & & & 0.09 & 0.09 & 0.10 \\
\hline External support & & & $0.14^{\dagger}$ & $0.15^{*}$ & $0.13^{\dagger}$ \\
\hline \multicolumn{6}{|l|}{ Interaction effects } \\
\hline Inseparability $\times$ Internal support & & & & $0.24 * * *$ & $0.18 * *$ \\
\hline $\begin{array}{l}\text { Inseparability } \times \text { External } \\
\text { support }\end{array}$ & & & & & $0.14 *$ \\
\hline F-Statistics & $5.92 * * *$ & $7.05 * * *$ & $6.65 * * *$ & $7.86^{* * *}$ & $7.72 * * *$ \\
\hline R-squared & 0.23 & 0.28 & 0.31 & 0.36 & 0.38 \\
\hline R-squared change & $0.23 * * *$ & $0.05 * * *$ & $0.03 *$ & $0.06 * * *$ & $0.01 *$ \\
\hline Adjusted R-squared & 0.19 & 0.24 & 0.26 & 0.32 & 0.33 \\
\hline
\end{tabular}

Dependent variable: digitalization of a service process

${ }^{\dagger} p<0.10, * p<0.05, * * p<0.01, * * * p<0.001$ 
step, we additionally included the interaction term between inseparability and external support for innovation (Model 5). Regarding our control variables, we discovered only two significant effects on digitalization: a negative effect of education and health services industry $(\beta=-0.22$, 95\% CI $[-0.37,-0.07]$, $p<0.01$, Model 1) and a positive effect of technology turbulence $(\beta=0.41,95 \%$ CI [0.23, 0.58], $p<0.001$, Model 1).

$\mathrm{H} 1$ predicts that inseparability of a service process is negatively associated with its digitalization. The effect of inseparability on the digitalization of a service process was negative and highly significant $(\beta=-0.26,95 \%$ CI $[-0.39,-0.12]$, $p<0.001$, Model 2). The entrance of inseparability provided an additional explanation power of $5 \%$, which was significant (R-squared change $=0.05$; $F=7.05, p<0.001)$. Therefore, $\mathrm{H} 1$ is supported: the higher the degree of inseparability of service processes, the lower the degree of their digitalization.

Entering the main effects of internal and external support for innovation on digitalization showed a non-significant positive main effect of internal support for innovation $(\beta=0.09$, 95\% CI [-0.06, 0.24], ns, Model 3), and a significant positive main effect of external support for innovation $(\beta=0.14,95 \%$ CI $[-0.01$, 0.29], $p<0.10$, Model 3). Entering the main effects of internal and external support for innovation provided an additional significant explanation power of $3 \%$ (Rsquared change $=0.03 ; F=6.65, p<0.001$ ).

$\mathrm{H} 2$ suggests that internal support for innovation weakens the negative effect of inseparability on digitalization. The interaction effect of inseparability and internal support for innovation on the digitalization of a service process was positive and significant $(\beta=0.18,95 \%$ CI $[0.05,0.31], p<0.01$, Model 5). Thus, the effect of inseparability on digitalization increases by 0.18 as internal support for innovation increases by one standard deviation, holding external support constant (Hayes 2017). Figure 1 illustrates this relationship. Only when $Z$-scores of internal support for innovation were below 0.55 (medium-to-low internal support), the effect of inseparability on digitalization was negative and statistically significant $(p<0.05)$. The entrance of the interaction effect of inseparability and internal support for innovation on digitalization in Model 4 added a significant contribution of $6 \%$ in explaining the variation in the digitalization degree of service processes (R-squared change $=0.06 ; F=7.86, p<0.001)$. Hence, $\mathrm{H} 2$ is supported: internal support for
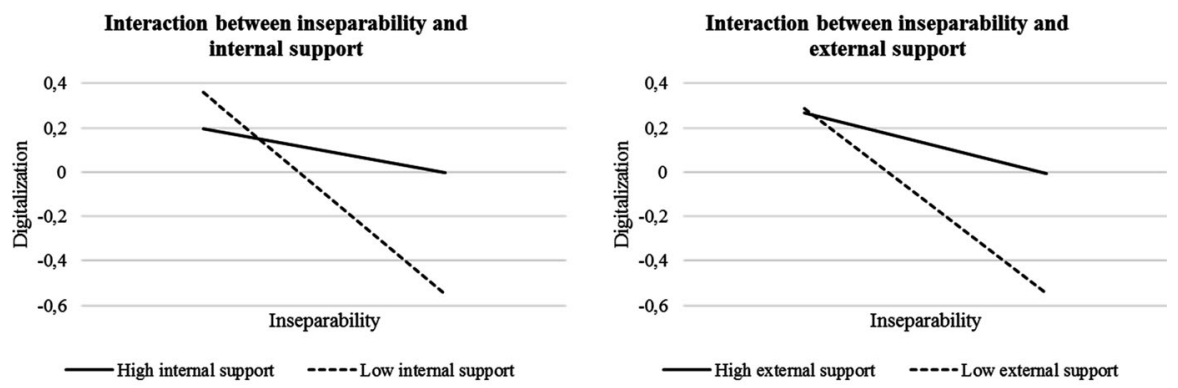

Fig. 1 Interaction between inseparability and internal/external support for innovation 
innovation moderates the relationship between the inseparability of service processes and digitalization, such that the negative effect of inseparability on digitalization is weaker the higher the degree of internal support for innovation.

$\mathrm{H} 3$ proposes that external support for innovation weakens the negative effect of inseparability on digitalization. The interaction effect of inseparability and external support was positive and significant $(\beta=0.14 ; 95 \%$ CI $[0.004,0.27], p<0.05$, Model 5). Thus, the effect of inseparability on digitalization increases by 0.14 as external support for innovation increases by one standard deviation, holding internal support constant (Hayes 2017). This interaction effect is also depicted in Fig. 1. For $Z$-scores below 0.46 (medium-to-low external support), the effect of inseparability on digitalization was negative and significant $(p<0.05)$. The entrance of the interaction effect of inseparability and external support for innovation on digitalization in Model 5 added a significant contribution of $1 \%$ in explaining the variation in the digitalization degree of service processes (R-squared change $=0.01$; $F=7.72, p<0.001)$. Thus, $\mathrm{H} 3$ is supported: external support for innovation moderates the relationship between the inseparability of service processes and digitalization, such that the negative effect of inseparability on digitalization is weaker the higher the degree of external support for innovation.

To ensure that our results were not biased by industry differences in inseparability and digitalization, we conducted robustness checks by: (1) utilizing different industry dummies: trade (10\% of the sample), health $(24 \%)$, scientific services and education (14\%), and finance and information (11\%), and (2) excluding all observations, belonging to education and health industry $(N=63)$. Our results remained robust for both variations. Furthermore, to prove that our results were not influenced by heteroscedasticity of unknown form, we repeated our analyses in Stata 14.1 utilizing heteroscedasticity-robust standard errors (Wooldridge 2012). All our results remained robust.

\section{Discussion}

\subsection{Summary of results}

Firms in different industries are starting to digitalize their service processes to stay competitive on the market (Hess et al. 2016). However, in doing so, they may face challenges, which arise due to inseparability of service processes (Green et al. 2016; Paluch and Blut 2013). In this study, we test if inseparability indeed presents an obstacle to the digitalization of service processes, and argue that this challenge can be mitigated through internal and external support for innovation. The results of our cross-industrial survey of service employees and managers confirm that the inseparability of service processes negatively influenced digitalization. This implies that the more inseparable a service process is, the more difficult it will be to digitalize this service process. As expected, this effect was mitigated by the internal and external support for innovation. Particularly, inseparability negatively influenced digitalization only when internal and external support for innovation was low. 
These results suggest that internal and external innovation support can be used to digitalize service processes despite a high degree of inseparability.

Additionally, our analysis of control variables also revealed that the digitalization of service processes was lower in the education and health services industry, and positively related to technologically turbulent environments. The first finding can be explained by these industries having often low budgets, which hinder the digitalization on top of inseparability (Lovelock and Gummesson 2004; Green et al. 2016; Moeller 2010; Javalgi et al. 2009). The second finding can be interpreted in the way that a higher rate of technology changes forces firms to implement new digital solutions to stay competitive on the market (Akgün et al. 2012). However, further research is necessary to examine the relationship and the explaining mechanisms between technology turbulences and the digitalization of service processes.

\subsection{Theoretical implications}

With these results, we extend service innovation research (Storey et al. 2016) by making three theoretical contributions. First, we provide empirical evidence on the hindering role of inseparability on the digitalization of service processes (Biemans et al. 2016). Hereby, we show that it may be more difficult to digitalize highly inseparable service processes than more separable ones (Overby 2008). With this finding, we are able to support the observations made by prior studies about a link between service process inseparability and physical service delivery empirically (Keh and Pang 2010; Dotzel et al. 2013). Transferring this finding into a broader service innovation context, we explore the role of inseparability as a hindering factor in the service innovation process (Biemans et al. 2016).

Second, we consider inseparability in line with the established studies from the service field as a matter of degree (Lovelock and Gummesson 2004), not of fact, as it has been done in service innovation research before (Storey et al. 2016). As inseparability of service processes incorporates more facets than just being present or not (Lievens and Moenaert 2000; Lovelock and Gummesson 2004), this allows us to address inseparability and its impact on the digitalization of service processes more precisely.

Third, we demonstrate that the hindering effect of inseparability on the digitalization of service processes can be mitigated through internal and external support for innovation. First, this means that inseparability of service processes should not be considered as an inevitable, but rather as a formable characteristic of service processes (Lovelock and Gummesson 2004; Vargo and Lusch 2004). Second, herewith, we show that internal (Stock et al. 2017) and external (Carbonell et al. 2009) support for innovation may present not only the direct antecedents of service innovation, but also the facilitating factors, which are able to mitigate innovation obstacles. With this finding, we also extend the list of outcomes (Storey et al. 2016) that can be addressed by internal and external support for innovation. 


\subsection{Practical implications}

Our results are important for practitioners, because many firms face the need to digitalize their service processes to stay competitive on the market (Hess et al. 2016). We empirically demonstrate that inseparability presents a major barrier to the digitalization of service processes. Yet, we also show that firms can digitalize service processes even when the service delivery is highly inseparable from a customer-if they can access internal and external support for innovation. Based on these results, we can provide concrete recommendations to firms that aim at digitalizing their service processes.

First, firms should be aware of the fact that inseparability can affect the digitalization of service processes. Inseparability can be expected to hinder digitalization due to the difficulty to transfer the direct contact to the customer and the synchronous actions to the digital environment. This difficulty might result in negative customer reactions and challenges for service providers during the delivery of the digitalized service. Thus, when planning digitalization projects, practitioners first need to carry out an assessment of their service processes. In doing so, they should investigate if their service process involves the presence of the customer when the service is produced and synchronous actions between the customer and the service provider. If the assessment reveals that the considered service processes are highly inseparable from customers, firms should be prepared to need additional efforts to digitalize their service processes.

Second, to mobilize these efforts, firms are well advised to draw from internal and external support for innovation. Firms should use internal and external support to find new solutions to conduct highly inseparable service processes in a more separable and digitalized way or to introduce new digital services that would replace the old ones. For securing internal support, firms should establish a culture of innovation by promoting innovation-oriented behaviors among their members and encouraging creative ideas within a firm. Concerning external support, firms can apply for governmental funding, search for cooperation with universities, involve customers in the digitalization process, and the like. Using both sources of innovation support, firms may be well equipped for overcoming the challenge of inseparability for the digitalization of their service processes.

\subsection{Limitations and future research}

While the application of a cross-industry sample supports the generalization of our results, we would like to mention some limitations of our study. First, utilizing a correlational design for our study does not allow us to determine a causal influence of inseparability as well as internal and external support for innovation on the digitalization of service processes. For instance, digitalization (Overby et al. 2010) may also change the characteristics of service processes. The emergence and increasing employment of innovative technologies in service processes could make them more separable by offering new possibilities to deliver services and interact with customers and, therefore, remove the synchronization of time and place between the provider and customer (Rust and Huang 2014; Paluch and Blut 2013; 
Moeller 2010). Furthermore, we cannot eliminate the risk of endogeneity, although we designed the survey with great care to limit it and implemented robustness checks with different control variables to test our results further. To address these causal issues, future research may apply longitudinal designs.

Second, we measured external support for innovation using knowledge and perceptions of our participants regarding their company and not by directly collecting data from each company's different external stakeholders. Thus, our measure indicates perceived rather than actual external support for innovation. Even though the existing research has also measured external support for innovation through employee knowledge and perceptions (Gumusluoğlu and Ilsev 2009), future research may collect data from multiple sources including a company's different external stakeholders.

Third, the data were collected with the help of an online panel provider. This is bound to three further limitations. The first limitation is that our sample might be biased in representing the preselection of participants registered with the online panel provider. Although we cannot rule out this potential selection bias, we made sure that only those who could be assumed to be knowledgeable about service processes, i.e., employees who either worked in a service process and/or were responsible for a service process, could participate in the survey. The second limitation arises as online panel participants might have an incentive to continue their survey participation to increase their remuneration. Hence, although the panel provider preselected participants to work in service industries, we are not able to verify how truthful the answers of our participants to the screen out question were. The third limitation refers to the fact that our sample consisted of people working in different organizations. This resulting heterogeneity in the sample might have hampered the detection of existing relationships (Shadish et al. 2002). Although we controlled for firm characteristics in terms of size, age, and industry in our analysis, future research may repeat our study using systematic data collection methods targeting specific employee groups, industries, or firm sizes.

Fourth, we have not measured the participants' experience with the development of new services. Specifically, employees who participated in new service development could have potentially had a more precise knowledge on the internal and external innovation support and could, thus, have assessed the degree of the innovation support differently. Hence, further research may also examine to what extent the experience with new service development (Yang et al. 2016) influences our research model.

Fifth, although we considered a cross-industry sample, the industry distribution in the sample could limit the generalizability of our results. In our sample, participants were mainly (57\%) employed in three industrial sectors: education and health services; trade, transportation, and utilities; and administration. Since, according to the German Federal Bureau of Statistics, nearly $60 \%$ of German service sector employees are working in the areas of trade, transportation, education, health, and public administration (Statistisches Bundesamt 2017), the sample distribution appears to be, overall, representative. Yet, future research needs to resample the distribution of industries narrowly to achieve a broader generalizability of results. 
Sixth, the generalizability of our results could be limited, because our study uses data from only one country: Germany. Indicating that our results are generalizable to many other countries, Germany was ranked twentieth among 48 countries in terms of national adoption of digital technologies, and, therefore, occupies an average position concerning its digitalization (Katz and Koutroumpis 2013). Thus, Germany does not appear to be on the extremes of either high or low digitalization. Nevertheless, cross-country samples may be helpful to examine the effects of inseparability as well as internal and external support for innovation on the digitalization of service processes further.

Acknowledgements This research was funded by the German Federal Ministry of Education and Research (BMBF) within the Program "Innovations for Tomorrows Production, Services, and Work" (02K14A080) and managed by the Project Management Agency Karlsruhe (PTKA). The authors are responsible for the contents of this publication.

Open Access This article is licensed under a Creative Commons Attribution 4.0 International License, which permits use, sharing, adaptation, distribution and reproduction in any medium or format, as long as you give appropriate credit to the original author(s) and the source, provide a link to the Creative Commons licence, and indicate if changes were made. The images or other third party material in this article are included in the article's Creative Commons licence, unless indicated otherwise in a credit line to the material. If material is not included in the article's Creative Commons licence and your intended use is not permitted by statutory regulation or exceeds the permitted use, you will need to obtain permission directly from the copyright holder. To view a copy of this licence, visit http:// creativecommons.org/licenses/by/4.0/.

\section{Appendix}

See Appendix Table 3. 
Table 3 Survey items

\section{Construct and items}

\section{Digitalization of service processes}

Service production and consumption encompasses all the activities within the scope of the actual act of the service delivery.

Service production and consumption...

1 ...takes place via an IT-based mechanism.

2 ...can be conducted from anywhere through an electronic interface.

3 ...can be conducted at any time through an electronic interface.

4 ...involves information storage in a digital form.

5 Overall, what percentage of service production and consumption takes place in an IT-based way according to your assessment? ${ }^{\mathrm{a}}$

\section{Inseparability ${ }^{\mathrm{b}}$}

6 The production of this service and the consumption of this service by the customer happen simultaneously.

7 The production process of the service is visible for the customer.

8 The customer consumes the service at the moment when the service is produced.

9 This service is rendered in direct contact with the client.

\section{Internal support for innovation}

In our company, ...

10 ...we particularly emphasize innovativeness and creativity.

11 ...we rate the flexibility of the employees very high.

$12 \ldots$...we are very open toward innovations (e.g., related to products and/or processes).

13 ...we expect that unbureaucratic solutions are found quickly in difficult situations (e.g., in cases of massive customer complaints).

14 ...we expect that new value-adding products and services are detected and developed permanently.

15 ...we appreciate unconventional ideas (especially if they come from the customer).

16 ...stories of exemplary innovation-oriented behavior of executives (e.g., founders, chief executives, managers) circulate.

17 ...attractive meeting and discussion areas (e.g., cafeterias or intranet) exist where information regarding innovations can be exchanged informally.

$18 \ldots$...we regularly organize events for customers or cooperation partners in the context of new product innovations.

\section{External support for innovation}

Please indicate below the extent to which your company has received resource- and/or knowledge-based support (e.g., financial support or technical assistance) for its innovation projects within the last 3 years from the following organizations:

19 Customers

20 Other companies

21 Research institutes/universities

22 Support organizations

23 Government

Market dynamism

24 In the market, customers' preferences change quickly over time.

25 Market demand and consumer tastes have been unpredictable.

26 In the market, customers tend to look for new products and services all the time. 
Table 3 continued

Construct and items

\section{Technology turbulence}

27 The technology in our market is changing rapidly.

28 Technological changes provide big opportunities in our industry.

29 It is very difficult to forecast where the technology in our industry will be in the next 2-3 years.

Intangibility $^{\mathrm{b}}$

30 This service concept is difficult for customers to understand.

31 It is difficult to illustrate the exact content or meaning of this service to the customer.

32 It is difficult to communicate the exact advantages of this service to the customer.

33 The customer has little tangible evidence during service delivery (physical equipment, personnel, and information technologies).

\section{Perishability $^{\mathrm{b}}$}

34 This service can create important capacity problems: we cannot store this service.

35 The demand for this service exceeds the capacity of branch personnel to deliver the service.

36 Demand for this service is not in line with service delivery capacity.

Unless otherwise indicated, the constructs were measured on a seven-point Likert scale from 1 (strongly disagree) to 7 (strongly agree). Internal support for innovation: items 10-15 belong to the subscale "values and norms"; items 16-18-to the subscale "artifacts".

${ }^{\mathrm{a}}$ Measured on a scale from 0 to $100 \%$

${ }^{\mathrm{b}}$ Measured on a five-point scale from 1 (to a very little extent) to 5 (to a very large extent)

\section{References}

Akgün, A.E., H. Keskin, and J. Byrne. 2012. Antecedents and Contingent Effects of Organizational Adaptive Capability on Firm Product Innovativeness. Journal of Product Innovation Management 29 (S1): 171-189.

Alam, I. 2006. Removing the Fuzziness from the Fuzzy Front-end of Service Innovations through Customer Interactions. Industrial Marketing Management 35 (4): 468-480.

Alexiev, A.S., M. Janssen, and P. den Hertog. 2018. The Moderating Role of Tangibility in Synchronous Innovation in Services. Journal of Product Innovation Management 35 (5): 682-700.

Ansoff, H.I. 1965. Corporate Strategy: An Analytic Approach to Business Policy for Growth and Expansion. New York: McGraw-Hill.

Arnold, T., E. Fang, and R. Palmatier. 2011. The Effects of Customer Acquisition and Retention Orientations on a Firm's Radical and Incremental Innovation Performance. Journal of the Academy of Marketing Science 39 (2): 234-251.

Barney, J. 1991. Firm Resources and Sustained Competitive Advantage. Journal of Management 17 (1): 99-120.

Barney, J. 2001. Resource-based Theories of Competitive Advantage: A ten-year Retrospective on the Resource-based View. Journal of Management 27 (6): 643-650.

Berry, L., K. Seiders, and D. Grewal. 2002. Understanding Service Convenience. Journal of Marketing 66 (3): $1-17$.

Biemans, W.G., A. Griffin, and R.K. Moenaert. 2016. New Service Development: How the Field Developed, Its Current Status and Recommendations for Moving the Field Forward. Journal of Product Innovation Management 33 (4): 382-397.

Bourgeois III, L.J. 1984. Strategic management and determinism. Academy of Management Review 9 (4): $586-596$. 
Carbonell, P., A.I. Rodriquez-Escudero, and D. Pujari. 2009. Customer Involvement in New Service Development: An Examination of Antecedents and Outcomes. Journal of Product Innovation Management 26 (5): 536-550.

Chang, W., and S. Taylor. 2016. The Effectiveness of Customer Participation in New Product Development: A Meta-Analysis. Journal of Marketing 80 (1): 47-64.

Chen, J.-S., H.-T. Tsou, and R. Ching. 2011. Co-Production and Its Effects on Service Innovation. Industrial Marketing Management 40 (8): 1331-1346.

Chen, J.-S., H.-T. Tsou, and A.Y.H. Huang. 2009. Service Delivery Innovation: Antecedents and Impact on Firm Performance. Journal of Service Research 12 (1): 36-55.

Cho, S.-E., and K. Park. 2003. Characteristics of Product/Service Process and Customer Needs of Geographical Accessibility in Electronic Commerce. International Journal of Service Industry Management 14 (5): 520-538.

Cloninger, P., and B. Oviatt. 2006. Measuring Service Content: A Scale Development. Thunderbird International Business Review 48 (5): 643-665.

Das, T.K., and B.-S. Teng. 2000. A Resource-Based Theory of Strategic Alliances. Journal of Management 26 (1): 31-61.

de Brentani, U. 1991. Success Factors in Developing New Business Services. European Journal of Marketing 25 (2): 33-59.

Dotzel, T., V. Shankar, and L.L. Berry. 2013. Service Innovativeness and Firm Value. Journal of Marketing Research 50 (2): 259-276.

Fichman, R.G., B.L. Dos Santos, and Z. Zheng. 2014. Digital innovation as a fundamental and powerful concept in the information systems curriculum. MIS Quarterly Executive 38 (2): 329-353.

Forkmann, S., S.C. Henneberg, L. Witell, and D. Kindström. 2017. Driver Configurations for Successful Service Infusion. Journal of Service Research 20 (3): 275-291.

Green, T., N. Hartley, and N. Gillespie. 2016. Service Provider's Experiences of Service Separation: The Case of Telehealth. Journal of Service Research 19 (4): 477-494.

Grover, V., R. Kohli, and P. Ramanlal. 2018. Being Mindful in Digital Initiatives. MIS Quarterly Executive 17 (3): 223-236.

Gumusluoğlu, L., and A. Ilsev. 2009. Transformational Leadership and Organizational Innovation: The Roles of Internal and External Support for Innovation. Journal of Product Innovation Management 26: 264-277.

Hair, J.F., W.C. Black, B.J. Babin, and R.E. Anderson. 2009. Multivariate data analysis, 7th ed. Englewood Cliff: Prentice Hall.

Hair, J.F., G.T.M. Hult, C.M. Ringle, and M. Sarstedt. 2013. A primer on partial least squares structural equation modeling (PLS-SEM). Thousand Oaks: Sage.

Hayes, A., and J. Matthes. 2009. Computational Procedures for Probing Interactions in OLS and Logistic Regression: SPSS and SAS Implementations. Behavior Research Methods 41 (3): 924-936.

Hayes, A. F. 2017. Introduction to mediation, moderation, and conditional process analysis: $A$ regression-based approach. 2 ed. Methodology in the Social Sciences Series. New York, NY: Guilford Publications.

Helfat, C.E., and R.S. Raubitschek. 2018. Dynamic and integrative capabilities for profiting from innovation in digital platform-based ecosystems. Research Policy 47 (8): 1391-1399.

Hess, T., C. Matt, A. Benlian, and F. Wiesböck. 2016. Options for Formulating a Digital Tansformation Strategy. MIS Quarterly Executive 15 (2): 123-139.

Hitt, M.A., and B.B. Tyler. 1991. Strategic decision models: Integrating different perspectives. Strategic Management Journal 12 (5): 327-351.

Ives, B., B. Palese, and J.A. Rodriguez. 2016. Enhancing Customer Service through the Internet of Things and Digital Data Streams. MIS Quarterly Executive 15 (4): 279-297.

Javalgi, R., W. Benoy Joseph, and R. LaRosa. 2009. Cross-cultural marketing strategies for delivering knowledge-based services in a borderless world: the case of management education. Journal of Services Marketing 23 (6): 371-384.

Josephson, B.W., J.L. Johnson, B.J. Mariadoss, and J. Cullen. 2016. Service Transition Strategies in Manufacturing: Implications for Firm Risk. Journal of Service Research 19 (2): 142-157.

Kamasak, R., M. Yavuz, and G. Altuntas. 2016. Is the relationship between innovation performance and knowledge management contingent on environmental dynamism and learning capability? Evidence from a turbulent market. Business Research 9: 229-253.

Kaplan, A.M., and M. Haenlein. 2006. Toward a Parsimonious Definition of Traditional and Electronic Mass Customization. Journal of Product Innovation Management 23 (2): 168-182. 
Katz, R., and P. Koutroumpis. 2013. Measuring Digitization: A Growth and Welfare Multiplier. Technovation 33 (10-11): 314-319.

Keh, H., and J. Pang. 2010. Customer Reactions to Service Separation. Journal of Marketing 74 (2): 55-70.

Lacity, M.C., R. Scheepers, and L.P. Willcocks. 2018. Cognitive Automation as Part of Deakin University's Digital Strategy. MIS Quarterly Executive 17 (2): 89-107.

Lievens, A., and R. Moenaert. 2000. Project Team Communication in Financial Service Innovation. Journal of Management Studies 37 (5): 733-766.

Lovelock, C. 1983. Classifying Services to Gain Strategic Marketing Insights. Journal of Marketing 47: 9-20.

Lovelock, C., and E. Gummesson. 2004. Whither Services Marketing? In Search of a New Paradigm and Fresh Perspectives. Journal of Service Research 7 (1): 20-41.

Martin, C. 2012. A Quarter of a Century: Reflections of the First 25 Years of the Journal of Services Marketing. Journal of Service Marketing 26 (1): 3-8.

McFarland, L., and R. Ployhart. 2015. Social Media: A Contextual Framework to Guide Research and Practice. Journal of Applied Psychology 100 (6): 1653-1677.

Melton, H.L., and M.D. Hartline. 2010. Customer and Frontline Employee Influence on New Service Development Performance. Journal of Service Research 13 (4): 411-425.

Miron, E., M. Erez, and E. Naveh. 2004. Do Personal Characteristics and Cultural Values That Promote Innovation, Quality, and Efficiency Compete or Complement Each Other? Journal of Organizational Behavior 25 (2): 175-199.

Moeller, S. 2010. Characteristics of services - a new approach uncovers their value. Journal of Services Marketing 24 (5): 359-368.

Ordanini, A., and A. Parasuraman. 2010. Service Innovation Viewed Through a Service-Dominant Logic Lens: A Conceptual Framework and Empirical Analysis. Journal of Service Research 14 (1): 3-23.

Ostrom, A.L., M.J. Bitner, S.W. Brown, K.A. Burkhard, M. Goul, V. Smith-Daniels, H. Demirkan, and E. Rabinovich. 2010. Moving Forward and Making a Difference: Research Priorities for the Science of Service. Journal of Service Research 13 (1): 4-36.

Overby, E. 2008. Process Virtualization Theory and the Impact of Information Technology. Organization Science 19 (2): 277-291.

Overby, E. 2012. Migrating Processes from Physical to Virtual Environments: Process Virtualization Theory. In Information Systems Theory: Explaining and Predicting Our Digital Society, ed. Y.K. Dwivedi, M.R. Wade, and S.L. Schneberger, 107-124. New York: Springer Verlag.

Overby, E., S. Slaughter, and B. Konsynski. 2010. Research Commentary-The Design, Use, and Consequences of Virtual processes. Information Systems Research 21 (4): 700-710.

Paluch, S., and M. Blut. 2013. Service separation and customer satisfaction. Journal of Service Research 16 (3): 415-427.

Pittaway, L., M. Robertson, K. Munir, D. Denyer, and A. Neely. 2004. Networking and Innovation: A Systematic Review of the Evidence. International Journal of Management Reviews 5-6 (3-4): 137-168.

Podsakoff, P.M., S.B. MacKenzie, J.-Y. Lee, and N.P. Podsakoff. 2003. Common Method Biases in Behavioral Research: A Critical Review of the Literature and Recommended Remedies. Journal of Applied Psychology 88 (5): 879-903.

Porter, M.E. 1980. Competitive Strategy: Techniques for analyzing industries and competitors. New York: Free Press.

Rust, R., and M.-H. Huang. 2014. The Service Revolution and the Transformation of Marketing Science. Marketing Science 33 (2): 206-221.

Sabherwal, R., and A. Jeyaraj. 2015. Information Technology Impacts on Firm Performance: An Extension of Kohli and Devaraj (2003). MIS Quarterly Executive 39 (4): 809-836.

Sambamurthy, V., A. Bharadwaj, and V. Grover. 2003. Shaping Agility Through Digital Options: Reconceptualizing the Role of Information Technology in Contemporary Firms. MIS Quarterly 27 (2): 237-263.

Saunders, M., P. Lewis, and A. Thornhill. 2007. Research methods for business students, 4th ed. Essex: Pearson Education.

Scott, S.G., and R.A. Bruce. 1994. Determinants of Innovative Behavior: A Path Model of Individual Innovation in the Workplace. The Academy of Management Journal 37 (3): 580-607.

Shadish, W.R., T.D. Cook, and D.T. Campbell. 2002. Experimental and quasi-experimental designs for generalized causal inference. Boston: Houghton, Mifflin and Company. 
Singh, R., L. Mathiassen, and A.N. Mishra. 2015. Organizational Path Constitution in Technological Innovation: Evidence from Rural Telehealth. MIS Quarterly 39 (3): 643-665.

Statistisches Bundesamt. 2017. Erwerbstätige: Deutschland, Jahre, Wirtschaftszweige (wz2008), Geschlecht. https://www.destatis.de. Accessed 28 May 2018.

Stock, R., and N. Zacharias. 2011. Patterns and Performance Outcomes of Innovation Orientation. Journal of the Academy of Marketing Science 39 (6): 870-888.

Stock, R., N. Zacharias, and A. Schnellbaecher. 2017. How Do Strategy and Leadership Styles Jointly Affect Co-development and Its Innovation Outcomes? Journal of Product Innovation Management 34 (2): 201-222.

Storey, C., P. Cankurtaran, P. Papastathopoulou, and E. Hultink. 2016. Success Factors for Service Innovation: A Meta-Analysis. Journal of Product Innovation Management 33 (5): 527-548.

Storey, C., and M. Hughes. 2013. The Relative Impact of Culture, Strategic Orientation and Capability on New Service Development Performance. European Journal of Marketing 47 (5-6): 833-856.

Thomas, M., D. Costa, and T. Oliveira. 2016. Assessing the Role of IT-enabled Process Virtualization on Green IT Adoption. Information Systems Frontiers 18 (4): 693-710.

Troilo, G., L.M. De Luca, and P. Guenzi. 2017. Linking Data-Rich Environments with Service Innovation in Incumbent Firms: A Conceptual Framework and Research Propositions. Journal of Product Innovation Management 34 (5): 617-639.

Vargo, S.L., and R.F. Lusch. 2004. The Four Service Marketing Myths: Remnants of a Goods-Based, Manufacturing Model. Journal of Service Research 6 (4): 324-335.

Vial, G. 2019. Understanding digital transformation: A review and a research agenda. The Journal of Strategic Information Systems 28 (2): 118-144.

Wooldridge, J. 2012. Introductory econometrics: A modern approach, 5th ed. Mason: South-Western Cengage Learning.

Xue, Y., H. Liang, and W. Boulton. 2008. Information Technology Governance in Information Technology Investment Decision Processes: The Impact of Investment Characteristics, External Environment, and Internal Context. MIS Quarterly Executive 32 (1): 67-96.

Yanadori, Y., and V. Cui. 2013. Creating Incentives for Innovation? The Relationship between Pay Dispersion in R\&D Groups and Firm Innovation Performances. Strategic management journal 34 (12): 1502-1511.

Yang, Y., P.K.C. Lee, and T.C.E. Cheng. 2016. Continuous improvement competence, employee creativity, and new service development performance: A frontline employee perspective. International Journal of Production Economics 171: 275-288.

Zeithaml, V., A. Parasuraman, and L. Berry. 1985. Problems and Strategies in Services Marketing. Journal of Marketing 49: 33-46.

Publisher's Note Springer Nature remains neutral with regard to jurisdictional claims in published maps and institutional affiliations. 